\title{
ENRIQUECIMENTO NUTRICIONAL DE RESÍDUOS DE ALGAS DO GÊNERO GRACILARIA SP. UTILIZANDO SACCHAROMYCES CEREVISIAE ATRAVÉS DE CULTIVO SEMISSÓLIDO
}

\author{
F.K.D. Dias', F.F.M. OLIVEIRA ${ }^{2}$, T.F. MARTINS ${ }^{3}$, L.G.O. MATIAS ${ }^{4}$ \\ Instituto Federal de Educação, Ciência e Tecnologia do Rio Grande do Norte \\ Universidade do Estado do Rio Grande do Norte ${ }^{2,4}$ \\ Universidade Federal do Ceará ${ }^{3}$ \\ kelia.dias@ifrn.edu.br
}

Artigo submetido em 29/09/2015 e aceito em 09/08/2019

DOI: 1015628/holos.2019.3451

\section{RESUMO}

Mulheres de corpo e alga, cooperativa criada na comunidade da Barrinha, Icapuí-CE utiliza algas marinhas criando produtos, gerando renda e resíduos. O objetivo é identificar os teores de proteínas totais (PT), de carboidratos solúveis totais (AST), umidade e cinzas nos resíduos, antes e depois da adição de diferentes concentrações da levedura $S$. cerevisiae, em diferentes tempos de exposição, buscando o tempo de fermentação adequado para melhorar a composição nutricional. As leveduras foram adicionadas nas concentrações de $0 \%$, 5\%. $10 \%$ e $15 \%$ e expondo em estufa à $36^{\circ} \mathrm{C}$ nos tempos de $0 \mathrm{~h}, 24 \mathrm{~h}, 48 \mathrm{~h}$ e $72 \mathrm{~h}$. A estatística foi feita usando o software Assistat ${ }^{\circledR}$,

montado em experimento fatorial, com três repetições, aplicando o teste de Tukey com $p<0,01$. Observou-se que o melhor tempo para aumento de PT foi $24 \mathrm{~h}$ na concentração de $10 \%$ (C2). A umidade mais adequada a legislação foi a amostra C3 atribuída a biomassa microbiana e as cinzas não apresentaram diferença significativa possivelmente devido ao consumo de AST para fabricação das proteínas. O resíduo, sendo estudado, pode servir como uma alternativa para o produtor rural, como ração animal.

\section{NUTRITIONAL ENRICHMENT OF GRACILARIA GENDER WASTE WASTE SP. USING SACCHAROMYCES CEREVISIAE THROUGH SEMI-SOLID CROP}

\begin{abstract}
"Body Women and seaweed", cooperative created in the Barry community, Icapuí-CE uses seaweed creating products, generating income and waste. The goal is to identify the levels of total protein (TP), total soluble carbohydrates (AST), moisture and ash in the waste before and after the addition of different concentrations of $\mathrm{S}$. cerevisiae at different exposure times, seeking time a suitable fermentation to improve the nutritional composition. Yeasts were added at concentrations of $0 \%, 5 \% .10 \%$ and $15 \%$ and exhibiting in an oven at $36^{\circ} \mathrm{C}$ for the times $0 \mathrm{~h}, 24 \mathrm{~h}, 48 \mathrm{~h}$ and $72 \mathrm{~h}$. Statistical analysis was done using the software Assistat ${ }^{\circledast}$ mounted in factorial experiment with three
\end{abstract}

replications, using the Tukey test with $p<0.01$. It was observed that the best time to increase in PT was 24 at $10 \%$ concentration (C2). The most suitable moisture legislation was the sample C3 attributed to microbial biomass and ash showed no significant difference possibly due to AST consumption for the production of proteins. The residue being studied can serve as an alternative for farmers, and animal feed.

KEY-WORDS: Semisolid fermentation, Saccharomyces cerevisiae, Algae, Waste. 


\section{INTRODUÇÃO}

O Brasil possui uma grande diversidade de macroalgas marinhas incluindo as pertencentes ao filo Rhodophyta com alguns gêneros de importância econômica, como a Gracilaria, Gelidium e Hypnea (CABRAL, 2010).

As macroalgas são do ponto de vista econômico, constituintes importantes sendo utilizadas para alimentação de homens e animais, além de servirem como matéria-prima para indústrias de diversos setores, através dos ficocolóides como as agaranas, carragenanas e alginatos (OLIVEIRA FILHO, 2001); (McHUGH, 2003).

O resíduo gerado no processo de extração de compostos de interesse comercial é rico em celulose, nitrogênio, potássio e, em menor quantidade sódio e fósforo, originários do meio ambiente marinho, onde é cultivada, e da matéria orgânica das células mortas da alga (REBOUÇAS, 2013). Os resíduos obtidos a partir do processo de extração não encontram ainda nenhuma aplicabilidade. Um dos destinos desse material pode ser o consumo animal, deve ser criteriosamente pesquisado.

O enriquecimento protéico de produtos naturais por bioprocesso em meio semissólido permite a obtenção de ração animal com valor nutritivo diversificado e adequado à dieta do animal estudado. Diversos produtos têm sido usados com sucesso para processamento protéico por fermentação microbiana: resíduos de batata-doce (YANG, 1988); bagaço de laranja (MENEZES et al., 1989); resíduos de mandioca (CANOILAS, 1991; MANILAL et al., 1991) e beterraba forrageira (GIBBONS et al., 1984).

Dentre os microrganismos destacam-se as leveduras, pela eficiência na bioconversão de produtos de menor valor nutricional a maior valor nutricional, reconhecidas como fonte protéica de alto valor e uma grande reserva natural de vitaminas do complexo B. As leveduras possuem valores nutritivos em termos de digestibilidade e valor biológico, em torno de $87 \%$, relativamente altos quando comparados aos totais do ovo de galinha, da ordem de $96 \%$ (PEPPLER, 1970).

A diversificação de substratos utilizáveis na fermentação semissólida, incluindo resíduos agrícolas e industriais, contribui também para minimizar os problemas de poluição no meio ambiente (CAMPOS, 2003). Além de servir como uma via de produção de alimentos alternativos, a qual elimina as restrições sazonais e de variações climáticas que existem em muitas safras agrícolas (SANTOS, 2013).

Diante disso, o objetivo consiste em avaliar os resíduos resultados do beneficiamento das algas produzidos pela atividade econômica da cooperativa Mulheres de Corpo e alga, antes e depois da utilização de processos fermentativos semissólidos com o fungo Saccharomyces cerevisiae, em diferentes tempos e concentrações, com diferentes complementos nitrogenados, visando o melhoramento nutricional do mesmo.

\section{REVISÃO BIBLIOGRÁFICA}

\subsection{Distribuição e importância econômica das algas no Brasil}


O filo Rodophyta, dominam as águas tropicais e quentes, mas também podem ser encontradas nas regiões mais frias do mundo. São predominantemente marinhas. A cor verde da clorofila a é mascarada pelo pigmento acessório ficoeritrina, que fica localizado no cloroplasto, característico deste filo, que dá a cor vermelha. Este filo representa as algas estudadas, todas pertencentes ao gênero Gracilaria, predominantemente três macroalgas vermelhas: Gracilaria caudata, Gracilaria birdiae e Gracilaria domingensis que apresentam a divisão Rodophyceae, classe Florideophyceae e ordem Gracilariales (1).

Atualmente a principal fonte econômica relacionada a estas espécies, é a exploração do agar, um ficocolóide de alto valor econômico. Os Ficocolóides $($ Ficos = alga + colóide = gel) são moléculas de grande tamanho, constituídas por açúcares simples, que fazem parte das paredes celulares e espaços intercelulares de um grande número de algas, fundamentalmente castanhas e vermelhas (SOUZA \& PAULA,2010).

$\mathrm{Na}$ Costa Brasileira ocorrem em diversos tipos de habitat, formando uma diversidade de ecossistemas. Os bancos de algas marinhas destacam-se por serem áreas de reprodução, alimentação e habitat da fauna. A grande riqueza genética dos ecossistemas marinhos brasileiros representa um imenso potencial pesqueiro, biotecnológico, mineral e energético (OLIVEIRA e MIRANDA, 1998).

A exploração, exclusivamente de forma extrativista de algas, estava localizada principalmente na costa do Ceará, mais especificamente no município de Icapuí. Neste período, na mesma localidade, cerca de $85 \%$ da matéria prima processada era coletada mensalmente, o equivalente a 60 toneladas (REBOUÇAS,2013).

\subsection{Banco de algas marinhas de Icapuí-CE}

O Município de Icapuí com 429,3 $\mathrm{Km}^{2}$ e $64 \mathrm{Km}$ de praia, está situado a $206 \mathrm{Km}$ de Fortaleza-CE. A praia da Barrinha está localizada a $6 \mathrm{Km}$ da sede do município e apresenta grandes valores naturais e paisagísticos. A região é caracterizada por um banco de algas popularmente conhecido como banco natural, importante como uma cobertura natural contra a erosão costeira (AQUASIS, 2003).

Para a comunidade da Barrinha, este ecossistema funciona como uma barreira de proteção contra a erosão marinha e sustenta toda a atividade pesqueira da região (REBOUÇAS, 2013). Apesar disto, o banco de algas e fanerógamas está vulnerável devido à extração indiscriminada e insustentável. Além de ameaçar o ecossistema, intimida todas as relações de subsistência que as populações costeiras possuem com este ambiente (FBC, 2012). Isso vêm contribuindo para a diminuição e escassez dos recursos pesqueiros da região (COSTA et al., 2012). 


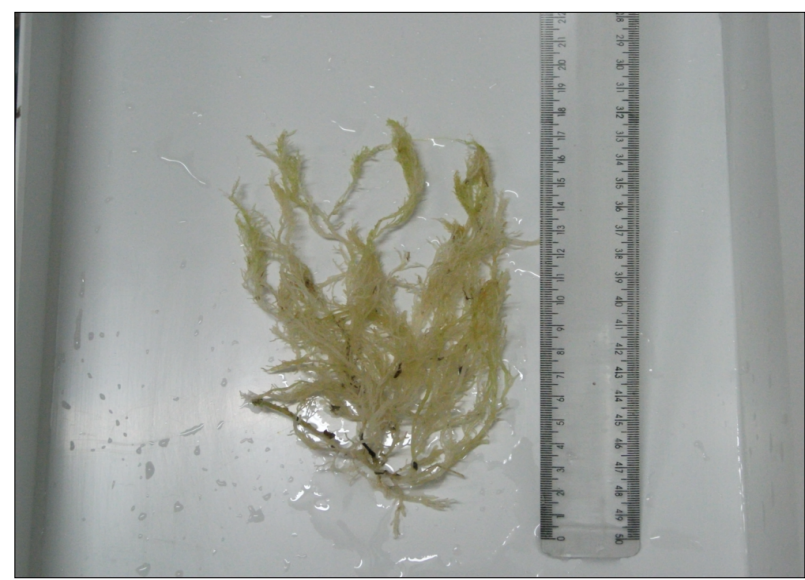

Figura 1: alga do gênero Gracilaria sp. , encontrada na praia da Barrinha,município de Icapuí-CE.

\subsubsection{Projeto mulheres de corpo e alga}

O projeto nasceu há quase 10 anos e hoje é meio de subsistência para as famílias que antes viviam da pesca da lagosta, hoje, quase extinta. O projeto substituiu a prática do extrativismo predatório pelo cultivo sustentável de algas, contribuindo para o equilíbrio do bioma marinho e ainda encontrando um meio de gerar renda com baixo impacto ambiental.

Foi desenvolvido pela FBC, através do Projeto "De Olho na Água", com capacitações oferecidas as mulheres da comunidade onde elas aprenderam a transformam algas marinhas em comida, sabonete líquido, sabonete em barra, xampu e hidratantes. Esses produtos são vendidos na própria sede do projeto e no comércio local, gerando renda para as famílias envolvidas (COSTA et al; ,2012).

As algas marinhas são a base de pratos servidos na merenda escolar nas escolas municipais de Icapuí. Segundo a coordenadora do projeto, Ana Paula Lima, este ano, serão cerca de 10 mil mousses produzidos somente para as escolas. O doce é vendido por $R \$ 1,40$, sendo que uma parte fica para um fundo de operação e reserva da fundação e o restante vai para as famílias envolvidas (MACHADO, 2014).

Com o cultivo houve uma recuperação significativa do banco de algas e, consequentemente, de toda biodiversidade que dele dependia para sobreviver. A colheita em mar aberto é feita pelos homens, por ser uma atividade que requer esforço físico; enquanto as mulheres ficam responsáveis pelo beneficiamento das algas, o que inclui lavagem, secagem e preparo dos alimentos e produtos de higiene para então transformar a matéria-prima em produtos de consumo (MACHADO, 2014).

Para manter a produção, a coleta das algas é feita em maré baixa, amarrando-as em cordas para que elas procriem e, após 90 dias, ser feita a colheita. 0 processo de lavagem utiliza a água da chuva armazenada em cisternas, minimizando o uso da água da rede de abastecimento local (MACHADO, 2014). 
Após processo de secagem é feito o cozimento das algas, de onde se extrai o Agar, um polissacarídeo utilizado como estabilizante na preparação de alimentos, conservas e cosméticos (MACHADO, 2014). O que sobra desse processo é o resíduo que pode ser aproveitado na horta caseira desenvolvida no projeto ou seu excesso é descartado sem finalidade.

\subsection{Processos fermentativos e bioconversão em leveduras}

Os microrganismos apresentam uma velocidade de multiplicação celular de aproximadamente 500 vezes maior que as dos vegetais. Isto ocorre em função da área específica dos microrganismos, o que Ihes proporcionam uma velocidade metabólica maior. Animais e vegetais necessitam de extensas áreas e de um ciclo longo para serem utilizados como alimento, enquanto os microrganismos podem produzir proteínas em poucas horas e em áreas restritas, o que os torna mais viáveis em termos de espaço (MENEZES, 1989).

Pelczar; Chan \& Krieg (2003) referem- se ao uso de microrganismos como alimentos e fontes atrativas de alimento, porque podem ser cultivados em despejos ou subprodutos industriais, com produção de vasta quantidades de células ricas em proteína.

As proteínas de microrganismos selecionados apresentam todos os aminoácidos essenciais; alguns microrganismos, em particular as leveduras, têm alto conteúdo de vitaminas; o meio de cultivo dos microrganismos é bastante diversificado, entre eles os dejetos ou subprodutos industriais, tais como: hidrocarbonetos de refinaria de óleo, líquidos com enxofre, hidrolisados de madeira (ARAúJO et al, 2009).

A eficiência da conversão protéica por leveduras depende de fatores como: temperatura, suprimento de oxigênio, disponibilidade de nutrientes. O tempo médio para dobrar o teor de proteína é de 5 horas em sistemas de fermentação por batelada (BURROWS, 1970 apud ARAÚJO, 2009).

Segundo Park \& Ramirez (1989), as leveduras de panificação Saccharomyces cerevisiae são organismos atrativos para a produção comercial de proteína em virtude de fácil propagação e de não terem relação patogênica com o homem. O uso de microrganismos como alimento ou como suplemento protéico tem atraído interesse, pois estes são capazes de crescer em diferentes tipos de subprodutos industriais, produzindo vastas quantidades de células, denominadas proteína unicelular ou proteína microbiana (PARAJÓ et al., 1995).

Em termos de digestibilidade, GIONGO, 2013 observou em seu trabalho que a FSS possivelmente causou a melhora da qualidade sensorial do produto, apresentando contribuições para o desenvolvimento de uma desejável textura, sabor e aroma do produto, fornecendo ao okara, resíduo oriundo da indústria de leite de soja, uma potencial característica de matéria-prima para a fabricação em alimentos.

\section{METODOLOGIA}


A coleta foi feita por moradores da comunidade da Barrinha, periodicamente ou sempre que é feito algum pedido a base do agar. Os homens da comunidade, geralmente os esposos das mulheres envolvidas no projeto utilizaram pequenos barcos e foram até as cordas onde as algas se fixam e cortam-nas, deixando a base da alga para uma nova germinação. Após a coleta no mar, em maré baixa, as algas foram transportadas até a estação de beneficiamento, onde foram retiradas as impurezas, como partículas sólidas, capim agulha entre outros detritos e essas foram lavadas e, essa água da lavagem, rica em sais foi usada como água solvente para fabricação de materiais de higiene e limpeza. Nas algas, foi usado o suco de limão (três limões para cada $8 \mathrm{Kg}$ de alga) deixando o mesmo agir por três minutos para que o ácido cítrico consiga descolorir, limpar e facilitar a retirada do Agar pelo calor.

As algas foram postas para secar ao sol em tanques de secagem por 24 horas, quando mudam de cor, de vermelha para amarela esbranquiçada. Quando bem secas, as algas foram colocadas em panelas de alumínio e adicionada água da torneira e posta para fervura no fogão convencional. Durante o processo de fervura, o Agar se desprende da alga, subindo junto com a água que, ao esfriar endurece como gelatina (2) (3).

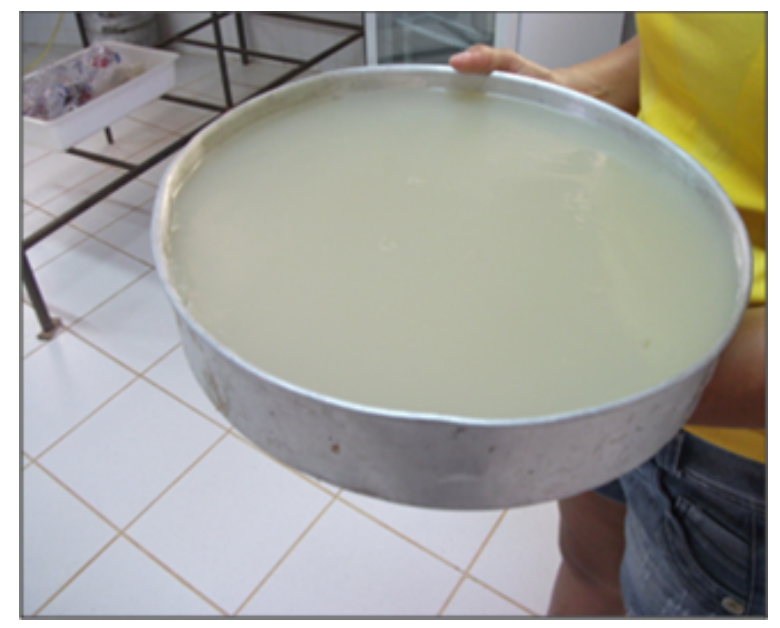

Figura 2: agar retirado da alga do gênero gracilaria sp. após fervura.

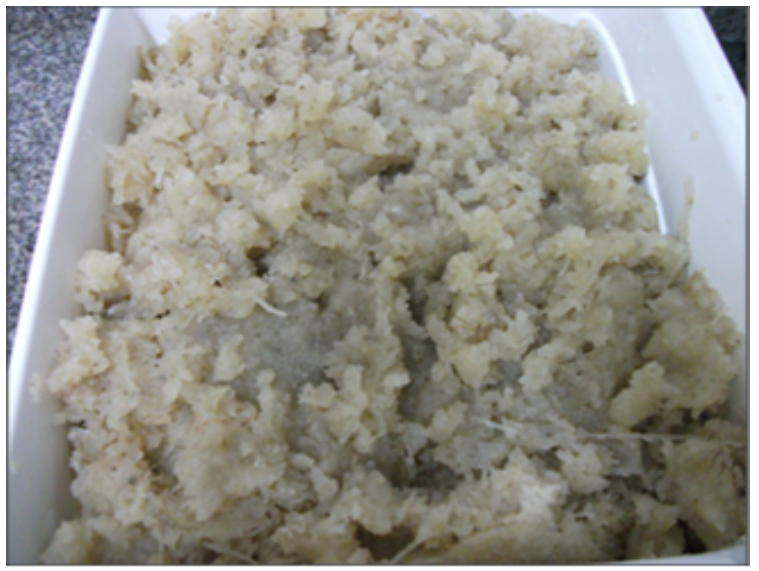

Figura 3: resíduo produzido a partir da retirada do agar. 
Desse procedimento, o que sobra na panela é o resíduo que foi imediatamente congelado sob o risco de degradação por microrganismos. Foram trazidos para a UERN, LABBIO-II, em Mossoró-RN, a 66,2 Km de Icapuí-CE.

O resíduo foi pesado em balança semi-analítica em frascos cobertos com papel alumínio identificados de acordo com a concentração de leveduras determinadas no modelo de delineamento experimental proposto. Foram postas para a esterilização em autoclave e expostos para atingir a temperatura ambiente $\left(25^{\circ} \mathrm{C}\right)$. $\mathrm{O}$ delineamento experimental encontra-se abaixo:
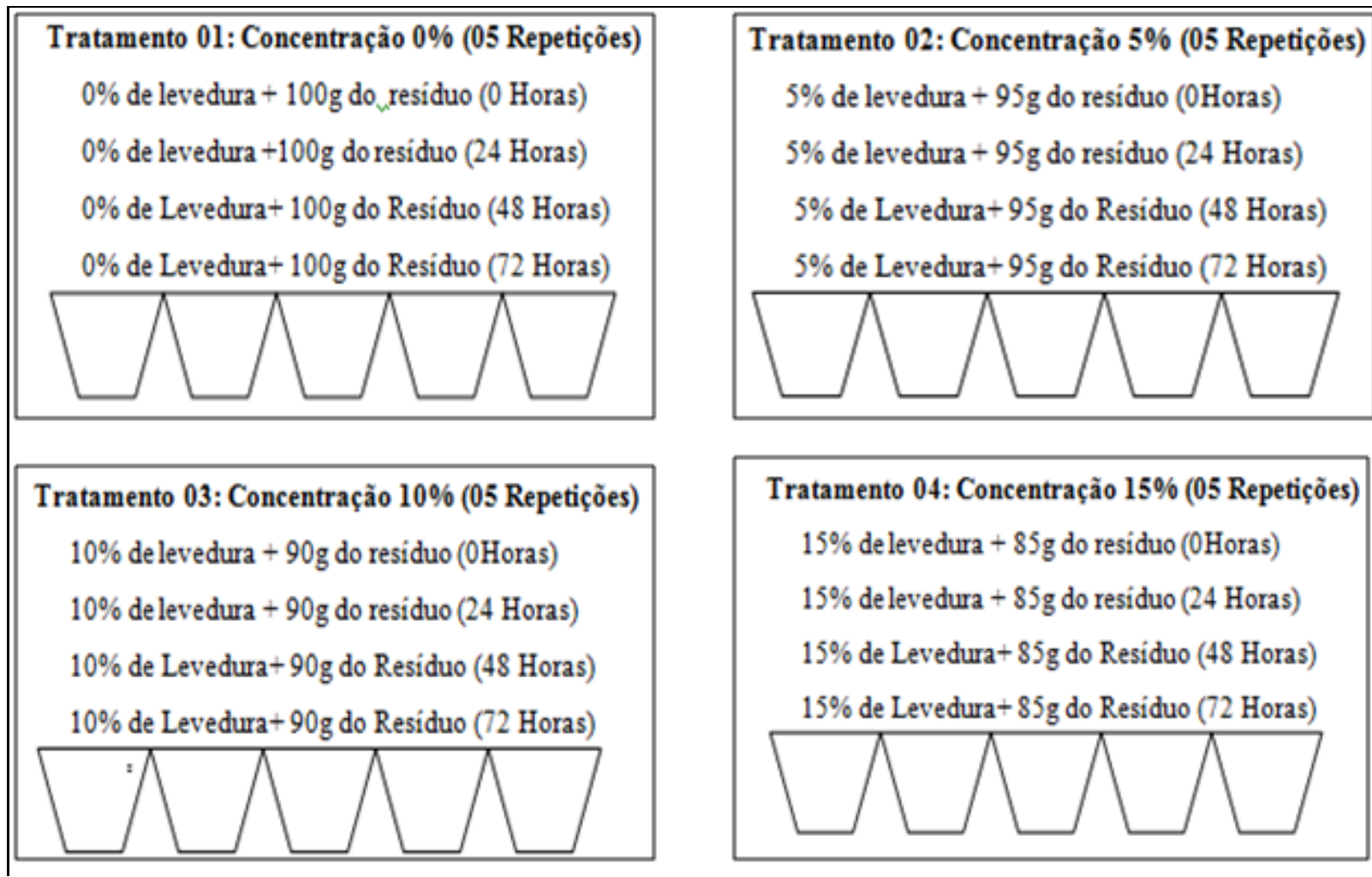

Tratamento 04: Concentração 15\% (05 Repetições)

$15 \%$ de levedura $+85 \mathrm{~g}$ do residuo (OHoras)

$15 \%$ de levedura $+85 \mathrm{~g}$ do residuo (24 Horas)

$15 \%$ de Levedura $+85 \mathrm{~g}$ do Residuo (48 Horas)

$15 \%$ de Levedura $+85 \mathrm{~g}$ do Residuo ( 72 Horas)

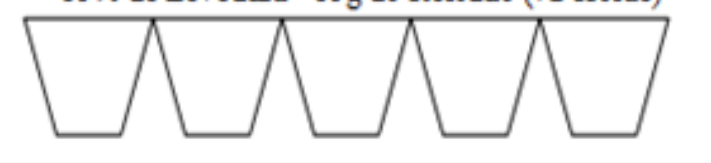

Figura 4: delineamento experimental dos tratamentos utilizados.

A levedura Saccharomyces cerevisiae, prensada, do tipo comercial, vendida como fermento biológico fresco, com umidade de $53,54 \%$ (base úmida) e teor médio de proteína bruta de $31,44 \%$ (base seca) foi inoculada em câmara de fluxo laminar, onde misturou-se bem o conteúdo com auxílio de um bastão de vidro esterilizado até formar uma massa homogênea de cor uniforme. Os frascos foram tampados novamente com o papel alumínio e postos em estufa bacteriológica à $36^{\circ} \mathrm{C}$. Dos 20 frascos de cada tratamento, 5 foram colocados na estufa de secagem, a uma temperatura de $100^{\circ} \mathrm{C}$, já sem a tampa de alumínio, logo após a homogeneização; 15 foram para a estufa bacteriológica à $36^{\circ} \mathrm{C}$. Com $24 \mathrm{~h}$, foram retirados 5 frascos, com $48 \mathrm{~h}$ foram retirados mais 5 frascos e, finalmente com $72 \mathrm{~h}$ foram retirados os 5 últimos frascos e foram colocados em estufa de secagem sem a tampa de alumínio até a secagem completa do produto. 
Quando estavam bem secas, as amostras foram processadas em liquidificador até formar um pó fino que foi empregado na análise de proteínas e carboidratos.

A determinação de proteínas foi feita através do método de Kjeldahl, (AOAC,1996), e convertido em porcentagem de proteína em base seca, empregando-se o fator de conversão 6,25 Kjeldahl (AOAC, 1996).

Para carboidratos solúveis totais, as análises foram feitas de acordo com Dubois et al. e baseia-se na determinação de açúcares simples, polissacarídeos e seus derivados incluindo os metil-ésteres com grupos redutores livres, após a desidratação dos mesmos pelo ácido sulfúrico e subseqüente complexação dos produtos formados com o fenol. A mudança da cor da solução é medida na região do visível e é proporcional à quantidade de açúcares presentes na amostra. A reação é sensível e de cor estável.

A umidade corresponde à perda em peso sofrida pelo produto quando aquecido em condições nas quais a água é removida. Na realidade, não é somente a água a ser removida, mas outras substâncias que se volatilizam nessas condições (ADOLF LUTZ,1985).

Cinzas de um alimento é o nome dado ao resíduo inorgânico que permanece após a queima da matéria orgânica, entre $550-570^{\circ} \mathrm{C}$, a qual é transformada em $\mathrm{CO}_{2}, \mathrm{H}_{2} \mathrm{O}$ e NO $\mathrm{N}_{2}$, assim sendo, a cinza de um material é o ponto de partida para a análise de minerais específicos. Estes minerais são analisados tanto para fins nutricionais como também para segurança (ADOLF LUTZ, 1985).

\section{RESULTADOS E DISCUSSÃO}

Foram feitas as análises de proteínas totais pelo método de microKjerdah/ no resíduo in natura e após FSS, nas quatro diferentes concentrações.Cruzando os fatores estatisticamente observamos que houve diferença entre as concentrações CO (grupo controle), C1 (5\%) em relação a C2(10\%) e C3 (15\%), pois o fator 1 (concentração) apresentou-se significativo ao nível de $1 \%$ de probabilidade $(p<0,01)$.

Porém, estatisticamente não ouve diferença entre os tempos propostos e não ouve significância também em relação à interação fator concentração e fator tempo.

Os dados percentuais de proteínas totais das amostras da primeira etapa apresentamse na tabela 1. Observou-se que ouve aumento do percentual protéico, que, estatisticamente apresentou diferença entre as concentrações Co (sem a levedura), as concentrações C1 (com $5 \%$ da levedura) e as concentrações C2 (10\%) e C3 (15\%) que, estatisticamente não apresentou diferença entre si. Pode-se observar ao ser comparado os valores das médias para o fator concentração, de acordo com o teste de Tukey para $p<0,01$ :

Tabela 1: Valores médios de Proteínas totais em função da diferença de concentração de Saccharomyces cerevisiae (fator 1) na etapa 1. 


\begin{tabular}{c|c}
$\mathrm{m} / \mathrm{m}$ & $\mathrm{mg} \mathrm{g}^{-1} \mathrm{MS}$ \\
\hline 0 & $16,38 \mathrm{c}$ \\
5 & $54,62 \mathrm{~b}$ \\
10 & $70,07 \mathrm{a}$ \\
15 & $67,88 \mathrm{a}$ \\
\hline $\mathrm{CV}(\%)$ & 5,61
\end{tabular}

Fonte: Assistat ${ }^{\circledR}$ versão 7.7 (2014)

Pode-se afirmar que, numericamente, entre as concentrações trabalhadas, os maiores percentuais de proteínas foram nas C2 e C3. Estatisticamente, as duas maiores concentrações não apresentaram significativa diferença, portanto priorizou-se a menor concentração, pois menos material fúngico seria utilizado para uma possível reprodução em larga escala pelo pequeno produtor rural.

A figura 5 mostrou o comportamento entre as concentrações das proteínas totais das amostras em diferentes concentrações de levedura, no decorrer dos tempos de exposição à levedura.

Figura 5: Concentração percentual das proteínas totais utilizando diferentes concentrações de Saccharomyces cerevisiae para enriquecimento protéico em resíduos de algas.

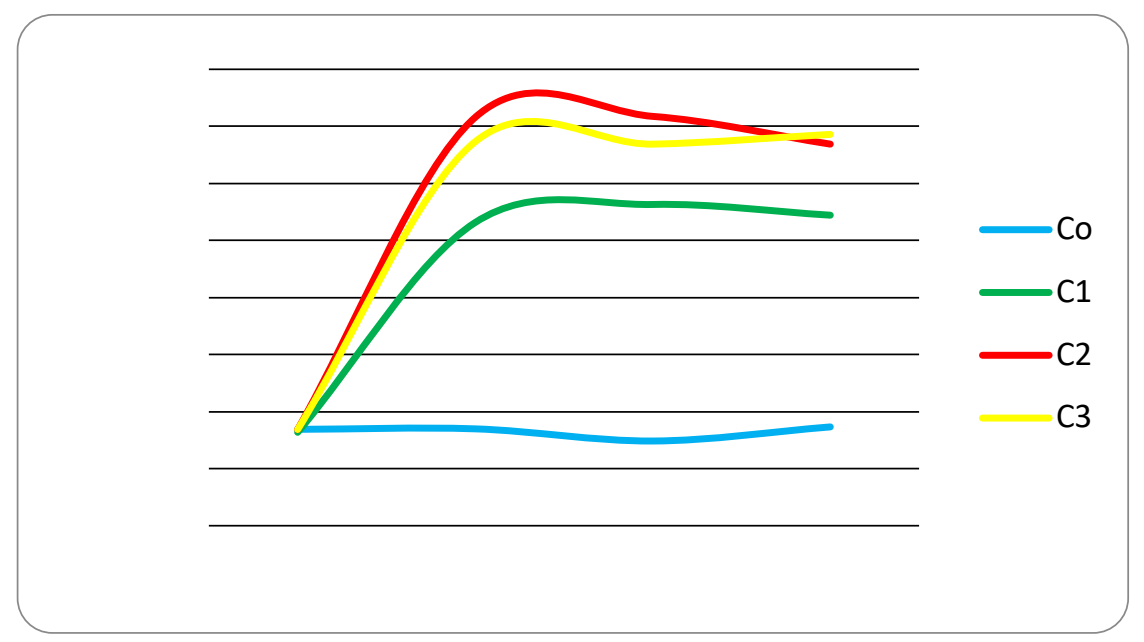

Fonte: o autor (2014).

Observou-se que, em todas as concentrações, mesmo que discretamente o pico maior de concentração das proteínas encontra-se no tempo de 24 horas e que a concentração de $10 \%$ (C2) da Saccharomyces cerevisiae foi a que apresentou um maior percentual de proteínas totais, sendo que, considerando o tempo de 24 horas ouve um 
aumento de 4 vezes o valor inicial (em comparação ao resíduo in natura) da proteína na concentração de $10 \%$ (C2) sendo então escolhido o tempo de $24 \mathrm{~h}$ e a concentração de $10 \%(C 2)$ para uma possível produção em larga escala.

Observou-se que os valores das proteínas totais, a concentração e o tempo de maior teor protéico apresentou-se condizente com o trabalho de Holanda et al. (1998), que fez a FSS utilizando pedúnculo de caju e a levedura Saccharomyces cerevisiae com uma inoculação de até $10 \%$ na pasta úmida do caju (suco + bagaço) e períodos de fermentação de até 72 horas, estes concluíram que o tempo ideal para a fermentação foi de 24 horas e proporcionou um teor protéico acima de $20 \%$ no material fermentado, viabilizando um concentrado protéico similar à torta de algodão.

Os carboidratos totais foram feitos nas mesmas variações de concentração e tempo de exposição à levedura para proteínas totais: (0\% (C0); $5 \%(C 1) ; 10 \%$ (C2) e 15\% (C3)) e submetidas à quantidade de tempo diferente de exposição ( $0 \mathrm{~h} ; 24 \mathrm{~h} ; 48 \mathrm{~h}$ e $72 \mathrm{~h}$ ).

Cruzando os fatores estatisticamente observou-se que ouve diferença entre as concentrações C0 (grupo controle), C1 (5\%), C2(10\%) em relação a C3 (15\%), pois o fator concentração apresentou-se significativo ao nível de $1 \%$ de probabilidade $(p<0,01)$. Numericamente e estatisticamente pode-se observar que a quantidade inicial de carboidratos solúveis total (AST) apresenta-se alta em relação às concentrações C1 e C2. Porém, em relação a C3 ela é estatisticamente irrelevante. A concentração de carboidratos solúveis totais na amostra controle (Co), mesmo após a retirada do agar se dar devido à alta concentração de carboidratos encontrados naturalmente nessa espécie de alga. No entanto, devido a bioconversão de carboidratos para proteínas devido ao aumento da biomassa fúngica, essa concentração diminuiu nas concentrações C1 e C2.

Ao comparar com a concentração C3, o teor de carboidratos aumenta novamente, corroborando a ideia de que a massa fúngica tenha chegado ao seu ápice de crescimento microbiano (fase log) na concentração $\mathrm{C} 2$ e, portanto pode estar havendo competição por nutrientes, por espaço ou deficiência nutricional fazendo com que a cultura fúngica entre na fase estacionária e, posteriormente a fase de morte celular ou declínio. O aumento da concentração de carboidratos se dar devido a morte fúngica e, consequentemente a contribuição dos carboidratos da própria massa fúngica junto a concentração de carboidratos solúveis totais analisados.

Já entre C1 e C2 foi observado que, numericamente ouve um discreto aumento do valor das médias, como pode-se observar na tabela 2 :

Tabela 2: Valores médios de AST em função da diferença de concentração de Saccharomyces cerevisiae (Fator 1) na etapa 1.

\begin{tabular}{c|c}
\hline $\begin{array}{c}\text { S. cerevisiae } \\
\mathrm{m} / \mathrm{m}\end{array}$ & $\begin{array}{c}\mathrm{AST} \\
\mathrm{mg} \mathrm{g}^{-1} \mathrm{MS}\end{array}$ \\
\hline 0 & $11,45 \mathrm{ab}$ \\
5 & $5,96 \mathrm{c}$ \\
10 & $8,29 \mathrm{bc}$
\end{tabular}




\begin{tabular}{c|c}
15 & $13,90 \mathrm{a}$ \\
\hline $\mathrm{CV}(\%)$ & 18,11
\end{tabular}

Fonte: Assistat ${ }^{\circledR}$ versão 7.7 (2014).

Para o tempo de exposição à levedura, observou-se estatisticamente que os mesmos não apresentaram significância entre eles quando considerado o teste de Tukey, com $\mathrm{p}<0,01$ como observou -se as médias.Diante disso, o melhor tempo numericamente para o teor de carboidratos solúveis totais é $72 \mathrm{~h}$. Isso pode ser explicado devido a fase na qual se encontra o cultivo fúngico.

Possivelmente com esse tempo a cultura fúngica esteja em declínio por competição, por escassez nutricional ou por limitação espacial, o que pode justificar o aumento na concentração de carboidratos solúveis do meio residual sendo "confundido" com os carboidratos solúveis totais advindos da própria massa fúngica. Segundo Rose \& Harrison, (1970) apud Pádua (1996); Scarinci et al. (1990), os carboidratos representam de 15 a 60 \% do peso seco das leveduras, sendo representados em média por, $27 \%$ de glucanas, $21 \%$ de mananas, localizados na parede celular, 12 \% de glicogênio e, $33 \%$ de trealose, carboidratos de reserva energética. A tabela a seguir mostra os valores das médias encontradas para concentração de carboidratos solúveis totais (AST) em miligramas por mililitros de amostra, nos diferentes tempos propostos e nas diferentes concentrações de Saccharomyces cerevisiae.O tempo foi insignificante estatísticamente, como para o tempo de proteínas totais.

Araújo et al.(2008), avaliando o valor maximizado para Energia bruta (EB) em palma forrageira encontrou que, após a FSS a EB foi de $3991 \mathrm{kcal} / \mathrm{g}$, equivalente ao aumento de $2 \%$ em relação ao teor de EB da palma forrageira in natura. Esse aumento significou que a palma possui carboidratos, principalmente monossacarídeos, na sua composição química, que podem ser utilizados pelas leveduras no processo de fermentação, além de ser considerada uma das principais fontes de calor e energia. No entanto o mesmo trabalho observou que não foram detectadas diferenças significativas $(P>0,05)$ entre os teores de energia bruta da palma forrageira nas concentrações de inóculos estudadas. Apesar de a levedura utilizar os carboidratos para síntese de proteínas, não houve redução no valor energético do bioproduto.

Comparando os dados referentes ao comportamento protéico nessas mesmas amostras, observou-se que, à medida que a proteína aumenta em concentração, os carboidratos estão diminuindo, porém muito sensivelmente em termos numéricos (6). Isso pode ser observado até as $48 \mathrm{~h}$ de exposição à levedura, o que corrobora a ideia de que as leveduras estão consumindo os carboidratos para produção de biomassa, uma vez que as próprias células leveduriformes são fontes de proteínas. 
Figura 6: Concentração de Açúcares solúveis totais e proteínas totais (PT) em $\mathrm{mg} / \mathrm{mL}$ utilizando diferentes concentrações de $S$. cerevisiae para enriquecimento protéico em resíduos de algas.

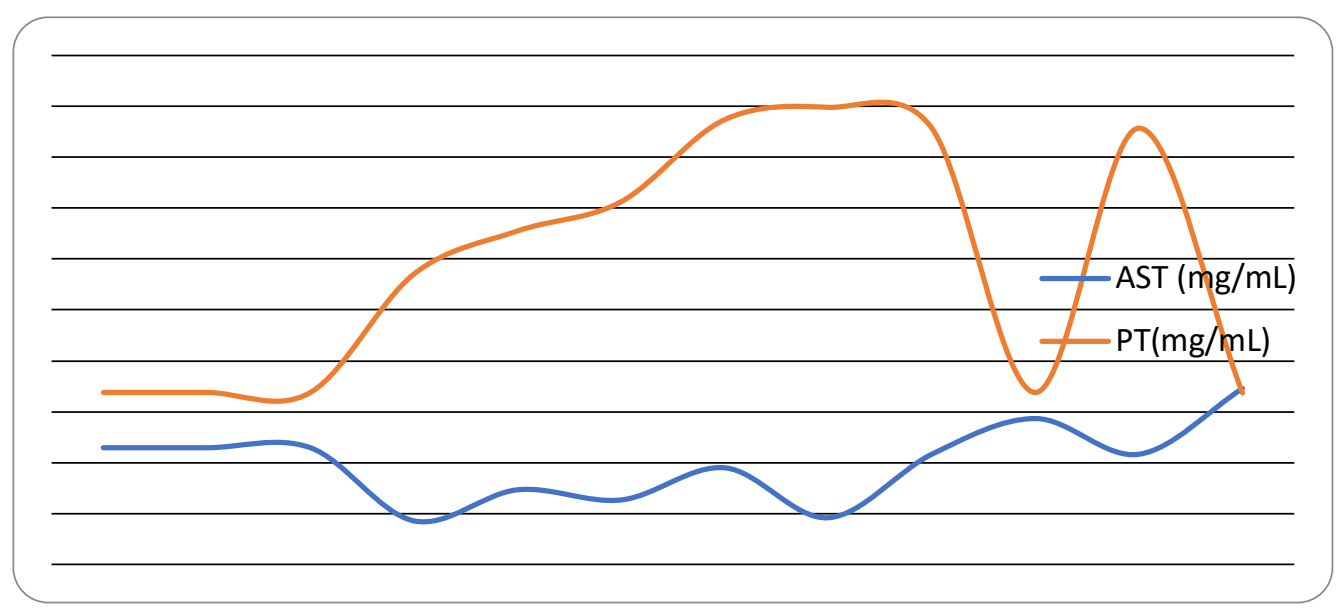

Fonte: Dados do autor (2014)

Um dos fatores que pode ter ajudado na interação microrganismo-substrato para otimizar a fermentação é a quebra dos compostos contidos no resíduo através do calor, utilizando o autoclave. Em muitos casos os substratos usados na FSS podem ser hidrolisados ou parcialmente hidrolisados através do uso de métodos físicos, químicos ou enzimáticos, facilitando assim a ação microbiana (KURBANOGLU, 2001 apud ALBUQUERQUE, 2003). O calor no processo de autoclavagem foi estudado no trabalho de GIONGO, 2013 que, sendo avaliou-se apenas o tempo inicial ( 0 hora), e foi comparado com a variação de isoflavonas agliconas para amostras não-autoclavadas e autoclavadas antes da fermentação pela Saccharomyces cerevisiae foi possível notar que nas amostras sem autoclavagem a concentração inicial da isoflavona aglicona é baixa e à medida que a fermentação ocorreu essa concentração teve um aumento gradativo, devido à bioconversão, já para amostras autoclavadas a concentração inicial da forma isoflavona aglicona aproximou-se a concentração máxima obtida, em relação ao teor de agliconas nas amostras brutas fermentadas. Essas características indicam que o processo de autoclavagem é responsável pela bioconversão das isoflavonas.

A umidade do substrato também deve ser considerada para que o fungo atinja o crescimento máximo. Altos índices de umidade resultaram na diminuição da produção por brotamento, interferindo na transferência de oxigênio (HOPPE et al, 2004). Já os baixos teores de umidade reduzem o crescimento fúngico.

O efeito do conteúdo de umidade do meio sólido sobre o crescimento microbiano pode ser mais bem expresso em termos de atividade de água (aw), que indica a quantidade de água disponível para o crescimento do fungo.

Foram testadas várias concentrações da levedura em diferentes tempos de exposição, o teste estatístico foi feito em esquema fatorial, com três repetições sendo que os tratamentos em relação as concentrações apresentaram diferença significativa ao nível de $1 \%$ de probabilidade $(p<0,01)$. A média da umidade apresenta-se na tabela abaixo: 
Tabela 3: Valor das médias das umidades entre os tratamentos, em diferentes concentrações de Saccharomyces cerevisiae na etapa 1.

\begin{tabular}{c|c}
\hline $\begin{array}{c}\text { S. cerevisiae } \\
\mathrm{m} / \mathrm{m}\end{array}$ & $\begin{array}{c}\text { Umidade } \\
\%\end{array}$ \\
\hline $\mathrm{C} 0(0 \%)$ & $92,94 \mathrm{a}$ \\
$\mathrm{C} 1(5 \%)$ & $53,71 \mathrm{~b}$ \\
$\mathrm{C} 2(10 \%)$ & $54,11 \mathrm{~b}$ \\
$\mathrm{C} 3(15 \%)$ & $9,37 \mathrm{c}$ \\
\hline $\mathrm{CV}(\%)$ & 3,24
\end{tabular}

Fonte: Assistat ${ }^{\circledR}$ versão 7.7 (2010)

A diminuição da umidade do resíduo na concentração C3 em relação ao controle e aos demais tratamentos pode ser explicada pela maior quantidade de massa fúngica adicionada ao meio de cultura de uma só vez, diminuindo a água disponível no meio uma vez que a umidade da S.cerevisiae (em forma de fermento em pó) é de aproximadamente $1,36 \%$ e a umidade do resíduo das algas era, no momento da inoculação da levedura de $92,93 \%$. Em seu trabalho, Araújo (2005), observou que para enriquecer, através de FSS a palma forrageira (uma cactácea), deve-se iniciar o processo com umidade acima de $90 \%$. Segundo o autor, a umidade mínima para o crescimento das leveduras é entre 75 e 95\%, mas também as mesmas suportam uma ampla variação.

O problema da ocorrência de fungos contaminantes em alimentos baseia-se em dois fatores: o seu alto poder de deterioração, relacionando ao fato de possuírem um alto arsenal enzimático, proporcionando-lhe a capacidade de colonizar os mais diversos substratos; e a sua capacidade de produzirem metabólitos tóxicos nos seres humanos e animais (BANWART, apud SOUZA et al, 2003; SOUZA et al, 2004). Se o teor de umidade estiver abaixo de $12 \%$ à capacidade de desenvolvimento do bolor é menor, pois haverá uma menor possibilidade de contaminação sendo então a concentração C3 mais adaptada ao processo de armazenamento.

Com relação às cinzas foi observado que, estatisticamente não houve diferença significativa entre nenhum dos tratamentos, incluindo as duas etapas da pesquisa, como mostra as tabelas abaixo:

Tabela 4: Valor das médias das Cinzas entre os tratamentos , em diferentes concentrações de $S$. cerevisiae.

\begin{tabular}{c|c}
$\begin{array}{l}\text { S. cerevisiae } \\
\mathrm{m} / \mathrm{m}\end{array}$ & $\begin{array}{c}\text { Cinzas } \\
\%\end{array}$ \\
\hline $\mathrm{CO}(0 \%)$ & $2,82 \mathrm{a}$
\end{tabular}




\begin{tabular}{c|c}
$\mathrm{C} 1(5 \%)$ & $3,57 \mathrm{a}$ \\
$\mathrm{C} 2(10 \%)$ & $2,58 \mathrm{a}$ \\
$\mathrm{C} 3(15 \%)$ & $3,99 \mathrm{a}$ \\
\hline $\mathrm{CV}(\%)$ & 52,31
\end{tabular}

Fonte: Assistat ${ }^{\circledR}$ versão 7.7 (2010)

Na legislação brasileira (BRASIL, 2005) conceituam-se as cinzas como o resíduo mineral fixo resultante da incineração da amostra do produto. Desta forma, estatisticamente o teor de cinzas dos resíduos fermentados não foi alterado. As cinzas são a fração mineral dos alimentos, e o aumento observado, mesmo numericamente deve-se às reduções na concentração da matéria orgânica.

De acordo com Paiva (1991), valores maiores que a tolerância máxima permitida pode ser também um indicativo de teores significativos de $\mathrm{Ca}, \mathrm{P}, \mathrm{Fe}$ e $\mathrm{Mg}$, como também, mais provavelmente, indicam contaminação por material estranho ao produto ocasionado por falhas em algumas etapas do processamento.

A média do teor de cinzas dos resíduos fermentados, se comparados com o trabalho de Rebouças (2013), cujo resíduo foi analisado in natura e o valor é em torno de $14 \%$, apresentou menor valor, nas duas etapas, o que pode ser justificado pelo consumo da matéria orgânica pela levedura para a produção de proteínas solúveis.

\section{CONCLUSÃO}

Os teores de proteínas e carboidratos mostraram ser inversamente proporcionais. Já que o aumento protéico, de acordo com a elevação da concentração de Saccharomyces cerevisiae, levou a diminuição de carboidratos no resíduo, comprovando que o microrganismo consome o açúcar presente no meio e produz proteína.

O aumento dos teores de proteína bruta dos substratos, após o enriquecimento protéico, apresentou resultados satisfatórios em relação aos valores destes nutrientes na forma in natura. Esse fato deve-se ao possível aproveitamento dos carboidratos solúveis disponíveis no resíduo pelas leveduras, por bioconversão a proteínas totais.

Houve enriquecimento protéico de 4,0 vezes mais para o maior nível de Saccharomyces cerevisiae. Um aumento significativo em relação ao resíduo in natura, o qual se apresenta pobre proteicamente. Esse aumento poderia ser maior se houvesse um controle maior sobre o $\mathrm{pH}$, uma vez que o mesmo pode ser um fator limitante para o crescimento microbiano.

A utilização de $S$. cerevisiae é viável, pois trata-se de um produto barato e facilmente encontrado. Sua utilização permite o reaproveitamento de resíduos alimentícios, como cascas de frutas, bagaços como uma forma alternativa de suplemento alimentar para animais, 
principalmente nas regiões em que é necessário economizar nos custos de produção. Por sua versatilidade de desenvolvimento, a $S$. cerevisiae pode servir como uma alternativa para enriquecimento e/ou disponibilização de nutrientes presentes em resíduos provenientes da indústria alimentícia.

\section{REFERÊNCIAS BIBLIOGRÁFICAS}

ALBUQUERQUE, P.M.Estudo da produção de proteína microbiana a partir do bagaço de maçã.Florianópolis:UFSC,2003.103p. Dissertação.

ASSOCIATION OF OFFICIAL ANALYTICAL CHEMISTS. Official Methods of analysis of the Association of Official Analytical Chemists(method 900.02). Arlington: A.O.A.C., 1996 chapter 44. p. 3.

AQUASIS (Associação de Pesquisa e Preservação de Ecossistemas Aquáticos). A Zona Costeira do Ceará: Diagnóstico para Gestão Integrada. Fortaleza: AQUASIS, 2003. 293p.

ARAÚJO, L.F; SILVA, F.L.H.da; BRITO, E. A; OLIVEIRA JÚNIOR, S; SANTOS, E.S. Enriquecimento protéico da palma forrageira com Saccharomyces cerevisiae para alimentação de ruminantes. Arquivo Brasileiro de Medicina Veterinária e Zootecnia, v. 60, n.2, p. 401-407, 2008. Disponívelem:<http://www.scielo.br/scielo.php?pid=S010209352008000200019\&script=sci a rttext\&tlng=pt $>$ Acesso em 12/01/2015.

ARAÚJO, L.F; SILVA, F.L.H.da; BRITO, E. A; OLIVEIRA JÚNIOR, S; SANTOS, E.S. Enriquecimento protéico da palma forrageira com Saccharomyces cerevisiae para alimentação de ruminantes. Arquivo Brasileiro de Medicina Veterinária e Zootecnia, v. 60, n.2, p. 401-407, 2009.

BRASIL. Ministério da Saúde. ANVISA. Resolução RDC n. 263, de 22 de setembro de 2005. Regulamento técnico para produtos de cereais, amidos, farinhas e farelos. Diário Oficial da República Federativa do Brasil, Brasília, DF, Seção 1, p.368-369, 2005.

BURROWS, S. Baker's yeast. In: ROSE, A.H.; AARRISON,J.S. (Eds). The Yeasts: yeast technology, London: Academic Prress,v.3, p.349-419, 1970.

CABRAL, G. Plantas multiuso. Algas podem ser usadas com fins alimentares, medicinais e cosméticos. Disponível em http://www.correiobraziliense.com.br. Acesso em 14/11/2014.

CAMPOS, A.R.N.; SANTANA, R.A.C.; DNTAS, J.P. et al.Enriquecimento protéico do bagaço do pedúnculo de caju por cultivo semi-sólido. Revista de Biologia de Ciências daTerra, v.5, p.1-11, 2003.

CANOILAS, L.M. Enriquecimento protéico de resíduos de farinha de mandioca pelo desenvolvimento de leveduras. Piracicaba: ESALQ, 1991. 110p. Tese de Mestrado.

COSTA, R. R.; MATIAS, L. G. O.; SOUZA, L. Estudo do teor de lipidios das macroalgas marinhas: Gracilaria caudata, Gracilaria birdiae e Gracilaria dominigensis para a produção de biodiesel. Resumo. Anais do XIV Congresso Brasileiro de Ficologia, 2012. 
DUBOIS, M.; GILLES, K. A.; HAMILTON, J. K.; REBERS, P. A.; SMITH, F. Colorimetric method for determination of sugars and related substances. Analytical chemistry. Washington, v.28, n.3, p.350-356, 1956.

FRAZIER, W.C., WESTHOFF, D.C. Microbiologia de los alimentos. Zaragoza: Acribia, 1993. p.274-300.

FUNDAÇÃO BRASIL CIDADÃO PARA EDUCAÇÃO, CULTURA, TECNOLOGIA E MEIO AMBIENTE FBC (Fortaleza, Ce). Ceará. Banco de dados. Icapuí - Ce, 2012.

GALVANI, F; GAERTNER, E. Adequação da metodologia Kjeldahl para determinação de nitrogênio total e proteína bruta. In: Embrapa Circular técnica, 63. Corumbá, 2006.

GIBBONS, W.R.; WESTBY, C.A.; DOBBS, T.L. A continous, farm-scale, solid-phase fermentation process for fuel ethanol and protein feed production from fodder beets. Biotechnology and Bioengineering. New York, v.26, p.1098-1107, 1984.

GIONGO, Camila Nascimento. Fermentação semissólida de okara com Saccharomyces cerevisiae r. f. bayanus visando a biotransformação de isoflavonas e melhoria da qualidade nutricional. 2013. 115p. Dissertação (Mestrado em Tecnologia de Processos Químicos e Bioquímicos) -Universidade Tecnológica Federal do Paraná. 2013.

HOPPE, J. M. et. al. Produção de sementes e mudas florestais, Caderno Didático no $1,2^{\underline{a}}$ ed.Santa Maria : [s.n.], 2004.388 p.

INSTITUTO ADOLFO LUTZ. Normas Analíticas do Instituto Adolfo Lutz.v. 1: Métodos químicos e físicos para análise de alimentos, 3. ed. São Paulo: IMESP, 1985. p. 27-28.KURBANOGLU, E. B. Production of single-cell protein from ram horn hydrolysate.Turkish Journal of Biology, v.25, p.371-377, 2001.

OLIVEIRA, E.C. \& MIRANDA, G.E.C. Aspectos sociais e econômicos da exploração de algas marinhas no Brasil. In Anais do IV Congresso Latinoamericano de Ficologia, Volume II Reunião Ibero-americana, VII Reunião Brasileira de Ficologia. Sociedade Ficológica da América Latina e Caribe Sociedade Brasileira de Ficologia, São Paulo, v.z p.359-369. 1998.

OLIVEIRA-FILHO, A. Estudos preliminares de macroalgas como indicadoras das condições ambientais da área recifal nas praias de Boa Viagem e do Pina, Pernambuco, Brasil. Monografia (Especialização) - Universidade Federal de Pernambuco. CTG. Departamento de Oceanografia. Gestão de Ambientes Costeiros Tropicais, 2001.

MACHADO, C. Mulheres de corpo e algas - Sustento que vem do mar.0 estado, Fortaleza,11 de Março de 2014. O estado verde. Disponível em:< http://www.oestadoce.com.br/noticia/mulheres-de-corpo-e-algas-sustento-que-vem-domar>. Acesso em: 23/11/2014. 
MANILAL, V.B.; NARAYANAN, C.S.; BALAGOPALAN, C. Cassava starch effluent treatment with concomitant scp production. World Journal of Microbiology and Biotechnology, Oxford, v.7, p.185-190, 1991.

McHUGH, D. J. Um guia para a indústria de algas. FAO Fisheries Technical Paper 441. 2003.

MENEZES, D.R. et al. Níveis de ureia em dietas contendo co-produto de vitivinícolas e palma forrageira para ovinos Santa Inês. Arq. Bras. Med. Vet. Zootec. [online]. 2009, vol.61, n.3, pp. 662-667. ISSN 0102-0935.

MENEZES, T.J.B.; SALVA, J.G.; BALDINI, V.L.; PAPINI, R.S.; SALES, A.M. Protein enrichment of citrus wastes by solid substrate fermentation. Process Biochemistry, London, p.167-171, Oct. 1989.

PADUA, D. M.C. Utilização da levedura alcoólica (Saccharomyces cerevisiae) como fonte protéica na alimentação de juvenis de pacu (Piaractus mesopotamicus, pisces, teleostei): aspectos metabólicos e de desempenho produtivo. Dissertação de Mestrado. UNESP: Jaboticabal, 1996, 133p.

PARAJÓ, J. C.; SANTOS, V.; DOMÍNGUEZ, H.; VÁZQUEZ, M. Protein concentrates from yeast cultured in wood hydrolysates. Food Chemistry, v.53,p.157-163, 1995.

PARK, S.; RAMIREZ, W.F. Dynamics of foreign protein secretion from Saccharomyces cerevisiae. Biotechnology and Bioengineering, New York, v. 33, p. 272, 1989.

PEDROSO, R. A. Avaliação da influência de amido e carragena nas características físicoquímicas e sensoriais de presunto cozido de peru. Dissertação de Mestrado. UEPG: Ponta Grossa, 2006, 74p.

PELCZAR, M.J., CHAN, E.C.S., KRIEG, N.R. Microbiologia. São Paulo : Makron Books, 2003. v.2, p.22-40.

PEPPLER, H.J. Food yeasts. In: ROSE, A.H.; HARRISON,J.S. (Eds). The yeast: tecnology. London: Academic Press,1970. v. 3, p.421-462.

REBOUÇAS, C. R. R. Estudo do teor de lipidios das macroalgas marinhas: Gracilaria caudata, Gracilaria birdiae e Gracilaria dominigensis para a produção de biodiesel. Dissertação de Mestrado. UERN: Mossoró, 2013,79p.

ROSE, A.H., HARRISON, J.N. The Yeast. London: Academic Press. 1970. v.3.

SCARINCI, H. E., UMANSKY, G., MENDOZA, M. S. C. Estudio de la composicion quimica de biomasas celulares de leveduras. Arch. Lationoam. Nutr., Guatemala,v.40, n.4, p.594-602, 1990. 
SILVA, D.J. Análise de alimentos: Métodos Químicos e Biológicos. 2. ed., Viçosa:UFV, Imprensa Universitária, 2009. 165p.

SOUZA,M.C.B;PAULA,P.O.C.Algas e suas diversas utilidades ao meio ambiente.2010.Universidade Federal do Rio Grande do Norte(UFRN):Natal, RN, 2010.

YANG, S.S. Protein enrichment of sweet potato residue with amylolitic yeasts by solid-state fermentation. Biotechnology and Bioengineering, New York, v.32, p.886-890, 1988. 